\title{
A Manaus dos imigrantes na ficção de Milton Hatoum
}

\section{The Immigrants' Manaus in the Works of Milton Hatoum}

\author{
YANA ANDreEva [yanaandreeva@abv.bg] \\ Софийски университет „Св. Климент Охридски“, Bulgaria
}

\begin{abstract}
RESUMO:
O artigo pretende apresentar um estudo da conjugação das problemáticas da imigração, da cidade e da identidade em Dois irmãos e Relato de um certo Oriente de Milton Hatoum. O tema da migração permeia os dois romances, aliando-se à exploração do processo de reconfiguração da identidade dos imigrantes e de seus descendentes. A identidade local das personagens vai sendo modelada pela convivência entre as diversas culturas dos imigrantes que residem em Manaus: portugueses, libaneses, judeus marroquinos, alemães. Ainda que frequente, o convívio nem sempre é pacífico, havendo episódios de incompreensão e intolerância, a revelar uma rivalidade ancestral no terreno das crenças religiosas. Tal convívio intercultural, misturando as velhas tradições das origens às imagens da nova terra, nutre o quotidiano de uma população urbana multicultural que, mesmo mantendo a ligação à identidade de nascença, se renova pelo contacto com o Outro.
\end{abstract}

\section{Palavras-chave:}

Narrativa brasileira contemporânea; Milton Hatoum; imigração; multiculturalidade

\section{Abstract:}

The paper examines the themes of immigration, identity, and the city in two novels written by Brazilian author Milton Hatoum. The symmetry of the fictional worlds in Hatoum's The Brothers and Tale of a Certain Orient helps the novels establish a peculiar dialogue. By using the Amazonian Port Manaus as a setting for their plots, the novels tell the dramatic stories of two families of Lebanese immigrants. Apart from being a potent subject in both novels, the topic of migration is also linked to that of the process of identity reconfiguration undergone by the immigrants and their descendants. The characters' local identity is shaped by their cohabitation with the various immigrant communities (such as the Portuguese, Lebanese, Jewish, and German communities) that populate the Amazonian town. The intercultural cohabitation, which combines the ancestral traditions with the images of the New World, fills the everyday life of a multicultural urban population which, despite maintaining its primary identity, keeps transforming itself through the contact with the Other.

\section{KEYWORDS:}

Contemporary Brazilian fiction; Milton Hatoum; immigration; multiculturality

RECEBIDO 2015-8-31; ACEITE 2016-1-30 
A ficção de Milton Hatoum constitui atualmente um dos melhores exemplos da insistente presença das temáticas da migração e da multiculturalidade na narrativa brasileira contemporânea. O objetivo desta abordagem das obras do autor é observar, a partir da interceção das perspetivas dos estudos literários, da antropologia cultural e da psicologia social, a maneira como se conjugam as problemáticas da imigração, da identidade e da cidade nos romances Relato de um certo Oriente e Dois irmãos. Ao recriar ficcionalmente o processo de transformação e identificação das identidades de personagens migrantes, ambos os romances revelam de um modo pronunciado o interesse pelos temas do inter-, trans- e multicultural, articulando-os com a identidade urbana e explorando-os por via de uma escrita literária ambígua, entre o ficcional e o autobiográfico.

Elegendo o vasto espaço da Amazónia e o palco urbano de Manaus como cenários da coexistência e do entrecruzamento de línguas, culturas e tradições, Milton Hatoum vai criar, nos textos aqui em apreço, universos ficcionais notáveis que se nos apresentam como uma homenagem do autor às suas origens libanesas e à importante contribuição dos imigrantes de origem árabe para a formação da sociedade brasileira contemporânea, já assinalada pelos estudos históricos e sociológicos que abordam as profundas repercussões da imigração árabe no desenvolvimento sócio-económico e cultural do Brasil (Mott 2000).

Impõe-se referir de início que Relato de um certo Oriente e Dois irmãos estabelecem entre si uma espécie de diálogo, fundamentado na simetria de seus universos ficcionais. Os dois romances têm como cenário da ação a cidade de Manaus e relatam as histórias dramáticas de famílias de imigrantes libaneses. As existências das personagens de Hatoum são marcadas por intensas e escuras paixões, pelo amor e pela violência, pela memória das origens ancestrais e pela busca de uma identidade nova, a corresponder-se com a realidade local e com as variadas culturas que a habitam. Além destas sugestivas coincidências, há também uma personagem-elo que transita do primeiro para o segundo romance - a matriarca Emilie que domina o espaço da primeira narrativa com a sua presença tutelar e que reaparece evocada no momento da morte de Zana, a matriarca no segundo romance.

Relato de um certo Oriente, publicado em 1989, é o romance de estreia de Milton Hatoum. Nele, a Amazónia e o Oriente fundem-se nas vivências íntimas dos membros de uma numerosa família árabe que reside em Manaus. Uma mulher, narradora não nomeada que busca as suas origens, regressa à cidade, onde transcorrera a sua infância. Dialogando por meio da escrita com seu irmão, que lhe escreve cartas de Barcelona, essa mulher solitária e vulnerável, rejeitada pela mãe e afastada da família de que é filha adotiva, vai procurar reerguer a sua identidade em crise reconstruindo a história familiar, reunindo os seus pedaços estilhaçados, juntando através do trabalho da memória os troços da história presenciada com uma outra história, que não testemunhou pessoalmente mas que lhe é narrada por outras personagens, seja em relatos orais (os do tio Hakim e da amiga da família Hindié Conceição), seja em anotações de diários e outros escritos que transcreve (os apontamentos do alemão Dorner, as cartas do irmão). Assim, em ordem propositadamente confusa e só aparentemente desconexa, a traduzir o trabalho árduo e inseguro de uma identidade a recompor-se, e por meio de várias vozes que reiteram a narração dos mesmos acontecimentos para introduzir uma visão ambígua, vão surgindo parcelas da vida da família, fragmentos de retratos, identidades de integridade ameaçada pela ausência e pelo esquecimento. 
A família de imigrantes libaneses, cuja história a narradora pretende reconstruir, é dominada pela figura de Emilie, mulher excecional que, mantendo-se fiel às suas raízes, preserva zelosamente as lembranças da juventude na terra natal. Cristã devota, esposa, mãe e avó dedicada, amante sensual, ela reina no espaço matriarcal da casa, impondo os hábitos da sua cultura ancestral. O seu marido é homem de poucos relacionamentos e muitas leituras, silencioso, absorto nas suas meditações e nas Suras do Alcorão. Além dos dois filhos adotivos (a narradora e seu irmão), o casal tem quatro filhos seus: o primogénito Hakim, Samara Délia, a filha estigmatizada por ter dado à luz uma criança surdo-muda e bastarda, e "os outros dois, inomináveis, filhos ferozes de Emilie" (Hatoum 2008: 9). Em torno à Parisiense, a loja cuja dependência a família habita, e depois em torno da nova casa, o sobrado, vão gravitar, numa presença ininterrupta ou alternativa, que faz lembrar as dilatadas estruturas familiares no Oriente Médio, muitas outras personagens: umas, escravizadas pelo afeto, sempre a acompanhar e servir a família, como Hindié e Anastácia Socorro; outras, espetrais, recordações de mortos que não abandonam os vivos, como Emir, o irmão suicida de Emilie; e outras ainda, peregrinas, como o fotógrafo alemão Dorner, de passagem por Manaus entre uma e outra viagem pelas terras do Brasil e do mundo.

Em Dois Irmãos (2000), Nael, filho bastardo que desconhece a identidade paterna, vai reconstruir, servindo-se da memória própria e alheia, a história da ruína de uma família de imigrantes do Líbano e de seus descendentes brasileiros. O drama familiar desta vez estrutura-se em torno do relacionamento conflituoso entre dois irmãos gémeos - Yaqub, homem ambicioso, decidido a progredir na vida, e Omar, o filho caçula, cuja existência se consome em vícios e aventuras, numa revolta contra a família que com o tempo vai perdendo o seu sentido. A rivalidade entre os dois irmãos vai marcar as suas relações com a mãe Zana, o pai Halim, a irmã Rânia e as mulheres que os gémeos amam. Cria-se assim entre as personagens uma intrincada teia de amor, ódio, vingança, paixões desmesuradas, sentimentos incestuosos, predileções e indiferenças, ciúmes violentos e reconciliações sensuais. Mais uma vez, o relato é conduzido por um narrador em busca de sua identidade. Desconhecendo quem é o seu pai, Nael vai construir para si uma identidade insegura, perambulando entre as diferentes culturas, vacilando entre as origens da mãe, a cunhantã Domingas, e a identidade dos patrões que o acolhem na família, identidade que é igualmente híbrida, pois incorpora na mundividência herdada das origens médio-orientais a cultura multirracial do espaço que cerca as personagens - o espaço de Manaus, cidade portuária à margem do Rio Negro, habitada por brancos, nativos e imigrantes, índios, negros e mulatos, por curumins e caboclos, turcos, indianos e alemães, um lugar de permanência e de passagem, lugar de todos e de ninguém, entre a selva devoradora de destinos e o oceano que separa das origens.

Para estudar a dimensão multicultural que se inscreve na construção da identidade das personagens nos romances de Hatoum, impõe-se refletir sobre sua condição de e/imigrantes numa grande cidade do Novo Mundo, como é a Manaus de inícios do século XX. A identidade individual e coletiva das personagens migrantes nas obras em apreço define-se com referência a uma série de aspetos que incidem sobre a sua identificação com o país de origem e o país de acolhimento. Assim, deveremos considerar os seguintes: a presença da cultura material e espiritual (culinária, objetos e artefactos, obras de arte, textos, etc.) dos seus países de origem em confronto, coexistência ou fusão com a cultura do país de acolhimento; as tradições e as crenças 
religiosas; os padrões de relacionamento familiar e afetivo; a vivência psicológica da diáspora nas gerações dos adultos e das crianças pela conservação/ perda da memória das origens; a preservação ou transformação da linguagem das origens em contacto com outras linguagens; afinal, a presença ou ausência de um diálogo entre as diferentes culturas.

O tema da imigração, como já ficou assinalado, permeia os dois romances. Para muitos dos imigrantes que escolheram o Brasil como destino, emigrar da pátria pobre equivale a realizar o sonho de enriquecer numa terra maravilhosa e distante, sonho que já nutrira a imaginação dos seus antepassados. Impressionado pelas cartas do seu tio Hanna que lhe descreviam um Brasil mirabolante, o marido de Emilie em Relato de um certo Oriente rememora numa longa conversa com Dorner o motivo da sua vinda para o Brasil: "O meu pai sentenciou: chegou a tua vez de enfrentar o oceano e alcançar o desconhecido no outro lado da terra" (Hatoum 2008: 65). O imigrante libanês não esquece as aflições pelas que tiveram de passar, em solo brasileiro, aqueles que sonhavam com a riqueza e evoca os que "desembarcam jovens e pobres para no fim da vida atormentada ostentarem um império" (idem, p. 56), lembrando o heroísmo dos que se embrenhavam no interior com sanha e determinação, enfrentando as feras e padecendo as febres, entregando-se ao vaivém incessante entre Manaus e a teia de rios.

As personagens de Hatoum associam a imigração a uma perda irreparável, à saudade, à dor da partida e à melancolia da ausência, a um desejo de evasão e de regresso à terra natal. O pai de Zana em Dois irmãos é quem cifra no seu triste destino esse sonho sempre acalentado pelo imigrante de regressar à sua terra como vencedor, para poder reencontar, antes de morrer, aqueles que ali deixou.

Estabelecendo-se no "outro lado da terra" (Hatoum 2008: 65), e no desejo de manter as marcas da diversidade cultural que constituem a sua identidade, os imigrantes vão procurar o refortalecimento dessa identidade por duas vias - ora pela perpetuação dos estereótipos culturais, ora pela insistente procura de analogias entre o espaço que os acolhe e a terra das suas origens, como acontece ao marido de Emilie que confessa ter escolhido Manaus por lhe ter lembrado de longe, com a cúpula do seu teatro, "uma mesquita que jamais tinha visto, mas que constava nas história dos livros da infância e na descrição de um hadji da minha terra" (Hatoum 2008: 68).

A observância de certas regras que configuram os padrões ancestrais de relacionamento no seio da família faz parte dessa adesão aos estereótipos culturais que mantêm nos imigrantes libaneses as suas identidades primordiais. Em ambos os romances se verifica a mesma distribuição de papéis entre os progenitores, circunscrevendo-se as suas figuras em espaços diferentes. A figura do pai é de certa forma externa ao lar, ou pelo menos transitória, cabendo à mãe, auxiliada por outras mulheres da família, novas ou mais velhas, o papel de educadora dos filhos, tanto dos filhos varões como das meninas. Assim, o primogénito Hakim de Relato de um certo Oriente é iniciado nos místérios da língua árabe pela mãe Emilie, apesar de que o pai, homem meditativo, asceta, leitor fervoroso das Suras do Alcorão, é quem por primazia tem acesso à mensagem oral e escrita da tradição. Em Dois irmãos, o pai Halim, também comerciante, numa nova reprodução dos estereótipos sociais e profissionais, é igualmente distanciado dos filhos e da sua educação. Obcecado pelo seu amor por Zana e sofrendo de terríveis ciúmes ao sentir o afastamento da mulher devido aos cuidados que esta tem que dedicar aos filhos, Halim vai desviar-se cada vez mais deles, criando um abismo na comunicação. A derradeira e trágica 
confirmação desse abismo entre pai e filhos é explicitamente representada no romance pelo monólogo acusativo do filho Omar frente ao cadáver de Halim.

Nas vidas dos imigrantes libaneses e dos seus descendendentes a cultura material e espiritual que os pais trouxeram consigo da pátria coabita, em confronto, justaposição e até fusão, com a cultura ou culturas do Brasil. A evocação das origens está sempre presente na profusão de objetos e artefactos exóticos de que se cercam ou que zelosamente preservam em secretos baús Emilie e o seu marido, em Relato de um certo Oriente: o narguilé de esferas de vidro brilhantes e com inscrustações de madrepérola, os potes contendo cânfora e benjoim, a vitrola que toca canções orientais, os frascos de perfume com notas de almíscar e âmbar, o hábito branco com manchas de bolor da noviça no mosteiro de Ebrin, as pulseiras de ouro, cujo número cresce conforme vai aumentando o número de filhos de Emilie.

Os objetos de culto, trazidos de longe, fazem parte desse ambiente íntimo que recria a terra natal com suas crenças e devoções. Emilie relembra as suas origens, cuidando zelosamente as suas estatuetas de santos de gesso, a Nossa Senhora da Conceição, o Menino Jesus, a Nossa Senhora do Líbano. O seu marido muçulmano guarda com o mesmo cuidado o tapete para rezar que tem no seu centro "num meio círculo desbotado pelo contacto assíduo de um corpo agachado para orar [...] uma caixa ou um cofre que encerra o Livro das revelações, representado por um pequeno quadrado amarelo" (Hatoum 2008: 39).

O respeito pelos cultos religiosos ancestrais que os libaneses praticam, sempre fervorosamente, é reforçado pelo acatamento de outros hábitos antigos das suas comunidades de origem, como são os hábitos da saudação, da leitura da sina ou do sacríficio ritual de animais. Em ambos os romances, abundam os episódios em que as tradições orientais são representadas com um alto grau de simbolização de entranhadas experiências, tanto individuais como coletivas. Tal é o episódio em que, ao receber o filho Yaqub que regressa do "degredo" oriental, Halim reproduz o ritual milenário da saudação oriental: "Apreensivo, ele se aproximou do moço, os dois se entreolharam e ele, o filho, perguntou: 'Baba?'. E depois os quatro beijos no rosto, o abraço demorado, as saudações em árabe” (Hatoum 2006: 11). Um poderoso imaginário oriental ressurge na evocação do costume de Emilie de ler a sina na borra do café:

Lembras como fazia Emilie - disse tio Hakim, sorvendo o último gole de café. - Ela pedia para que todos emborcassem a xícara na bandeja, e depois examinava o fundo de porcelana para decifrar no emaranhado de linhas negras do líquido ressequido o destino de cada um (Hatoum 2008: 27).

Mas é nas celebrações tradicionais que mais se aviva a pertença às raízes. Na opulência sensualista das festas na casa de Zana, em Dois irmãos, ou nos ritos de sacrifício festivo de animais na casa de Emilie, em Relato de um certo Oriente, o atavismo das origens explode como um paroxismo, como um acesso simultaneamente de prazer e de dor, júbilo e agonia, incompreensíveis para a geração dos descendentes, já sem vínculo direto com a pátria dos pais. Mesmo sem captar na integridade o cúmulo de sensações provocadas nos convivas pelo ato do sacrifício e pela cerimónia gastronómica que se lhe segue, os filhos intuem no exotismo dos gestos um saber milenário e misterioso que os atrai, unindo-os com força às origens dos progenitores. Um desses episódios de intenso convívio entre os imigrantes da primeira geração é recriado através 
do relato de Hakim que, por meio de uma admirável poetização da arte de preparar e consumir os alimentos, reproduz o sensualismo primitivo do sacrifício do carneiro e do hábito milenar de comer com as mãos o fígado cru do animal sacrificado.

O exotismo dos temperos e dos ingredientes da culinária árabe acompanha nas festas e no dia-a-dia os imigrantes, desencadeando, nos mais idosos, uma rememoração do passado pelo paladar e pelo olfato e a entrega aos prazeres dos sentidos. Nos mais novos, que desconhecem a terra dos pais, cria o gosto da abundância e do sabor excecional. A comida faz surgir, assim, o mágico encanto dum Oriente aromático, doce e sensual, distante no espaço, mas próximo dos sentidos. Encontramos em Dois irmãos e Relato de um certo Oriente inúmeras referências a ervas e especiarias (menta, tomilho, zatar, i.é. mistura de menta e tomilho, hortelã, pimenta-de-caiena, gergelim, canela, sumagre, açafrão), a suculentos pratos de carneiro e cheirosos guisados de lentilhas, à rica doçaria árabe, numa quase infinita enumeração de iguarias: "os pastéis de picadinho de carneiro, os folheados de nata e tâmaras, e o arroz com amêndoas, dourado, exalando um cheiro de cebola tostada" (Hatoum 2008: 86).

A língua falada pelas personagens de Milton Hatoum é aquilo que mais define suas identidades individuais e coletivas. Podem-se observar, conforme as personagens e as gerações, graus variados na preservação ou transformação da linguagem das origens no contacto com outras línguas. Um sinal evidente da filiação das personagens na cultura-mãe do Oriente Médio é-nos proporcionado pelos seus nomes. Os antropónimos de origem árabe escolhidos para identificar as personagens (Hakim, Samara, Soraya, Zana, Halim, Yacub) codificam o sentido da sua presença individual e também a sua projeção na história da família. Mas a marca decisiva para a definição identitária das personagens é a escolha da língua de expressão. Os imigrantes da primeira geração vieram ao Brasil já com a sua língua e não sem dificuldades aprenderam a usar o português no quotidiano. Mesmo depois de ter vivido alguns anos no Brasil, Emilie reconhece o seu embaraço em falar a nova língua quando, avisada pelo marido de que teriam de regressar ao Líbano por falta de dinheiro, replica que lá não precisará "gaguejar nem consultar dicionários para falar o que der na telha" (Hatoum 2008: 22), manifestando assim a sua falta de adaptação à realidade linguística do Brasil. Acostumando-se, ao passar dos anos, ao linguajar misturado da população manauara que incorpora no português vocábulos provenientes de outras línguas, os imigrantes dessa primeira geração vão retomar o uso do árabe só em ocasiões exclusivas: nas rezas, nas confidências ou nos instantes de grande afeto. Hakim, filho de Emilie, corrobora o uso do árabe por parte da primeira geração, parecendo-lhe esse idioma misterioso e incompreensível:

Já estava me habituando àquela fala estranha, mas por algum tempo pensei tratar-se de uma linguagem só falada pelos mais idosos; ou seja, pensava que os adultos não falavam como as crianças. Aos poucos me dei conta de que eles gesticulavam mais ao falar naquele idioma, e houve casos em que intui ideias através de gestos (Hatoum 2008: 44).

Tal uso ocasional do árabe por parte dos imigrantes idosos parece confirmar a quase supressão da língua materna, em favor da aquisição da língua do país que os acolhe. Mas há vezes em que a língua das origens brota, inconscientemente e sempre associada à emoção: os palavrões são pronunciados em árabe, e em momentos de aflição, quando não conseguem articular pala- 
vra em português, passam a falar torrencialmente na língua oriental, sem sequer aperceber-se da incomunicabilidade da situação, como acontece com Hindié quando telefona ao médico para avisar do acidente que Emilie sofrera e pedir auxílio.

Mais uma vez será Hakim, o filho escolhido para servir de interlocutor à mãe na sua língua ancestral, quem explicitará o bilinguismo de sua geração de descendentes de imigrantes e, com ele, sua dupla identidade, suas duas maneiras de ser e agir, como homem ocidental e levantino:

Desde pequeno convivi com um idioma na escola e nas ruas da cidade, e com outro na Parisiense. $\mathrm{E}$ às vezes tinha a impressão de viver vidas distintas. Sabia que tinha sido eleito o interlocutor número um entre os filhos de Emilie: por ter vindo ao mundo antes que os outros? Por encontrar-me ainda muito próximo às suas lembranças, ao seu mundo ancestral onde tudo ou quase tudo girava ao redor de Trípoli, das montanhas, dos cedros, das figueiras e parreiras, dos carneiros, Junieh e Ebrin? (idem, 46).

As lições de árabe que a mãe começa a dar a Hakim, ensinando-lhe a pronúncia das palavras e o "alifebata" (engenhosa e encantadora corruptela de "alfabeto", com que Emilie substitui o alfa e o beta gregos como origem da escrita ocidental, remetendo essa procedência para o espaço do imaginário oriental e das aventuras de Ali Babá), são para o jovem uma experiência de iniciação que lhe revela um novo mundo, em que sons e cadências diferentes vão nomear novas realidades. Nessa aprendizagem iniciática a realidade sensualista dos objetos vai conduzir a língua que os nomeia, aderindo a eles, e assim a língua, a pouco e pouco, vai desvendar o mundo.

Pela sua condição única de efetivamente bilíngue entre os filhos do casal de imigrantes e por ser simultaneamente brasileiro e libanês, Hakim é quem vai veicular no romance a reflexão sobre a maneira como a linguagem expressa e constitui a identidade. Na perspetiva de Hakim, será a língua o que vai definir a pertença e a cidadania do indivíduo. Sobretudo quando se trata de um indivíduo que vive numa grande cidade, espaço por excelência multicultural, visto que concentra em si a alteridade dos outros, possibilitando assim a identificação do sujeito não apenas com o que lhe é próprio, mas também com o que é diferente. Essa consciência de que a língua é ao mesmo tempo o primeiro e o último vínculo com as raízes generaliza-se, extendendo-se não só aos imigrantes e seus descendentes, mas igualmente a todos aqueles que vivem em situações de contactos interculturais.

As situações de interculturalidade fazem parte da vida das personagens de Hatoum que por sucessivas gerações habitam o espaço multiétnico e multirracial de Manaus. A geração dos primeiros imigrantes e também a geração dos seus descendentes vão viver um intenso convívio entre culturas, de que nos dois romances abundam as referências. No restaurante de Galib, pai de Zana, em Dois irmãos, reúnem-se imigrantes de diversas nacionalidades, transformando a simples passagem por um espaço urbano comum numa oportunidade de confidenciar projetos e falhanços, dores íntimas e amarguras:

Por volta de 1914, Galib inaugurou o restaurante Biblos. [...] O pai conversava em português com os clientes: mascates, comandantes de embarcações, regatões, trabalhadores do Manaus Harbour. Desde a inauguração, o Biblos foi um ponto de encontro de imigrantes libaneses, sírios e judeus 
marroquinos que moravam na praça Nossa Senhora dos Remédios e nos quarteirões que a rodeavam. Falavam português misturado com árabe, francês e espanhol, e dessa algaravia surgiam histórias que se cruzavam, vidas em trânsito, um vaivém de vozes que contavam um pouco de tudo: um naufrágio, a febre negra num povoado do rio Purus, uma trapaça, um incesto, lembranças remotas e o mais recente: uma dor ainda viva, uma paixão ainda acesa, a perda coberta de luto, a esperança de que os caloteiros saldassem as dívidas. Comiam, bebiam, fumavam, e as vozes prolongavam o ritual, adiando a sesta (Hatoum 2006: 36).

Passadas décadas, a filha do libanês Garib, Zana, vai reunir nas suas festas amigos e vizinhos de etnias e culturas diferentes, o neto Omar vai amar mulheres de outras raças e o bisneto, o curumim Nael, vai sentir palpitar na sua identidade imprecisa a mistura da herança da mãe índia e do pai árabe.

O convívio entre culturas faz parte do quotidiano dos imigrantes de Manaus, que moram em casas vizinhas, conhecem a vida do outro, respeitam os seus hábitos e crenças e muitas vezes lhe oferecem um apoio fraterno nos transes da vida. A cidade multiplica os relacionamentos humanos e amplia o perímetro das alianças e da solidariedade. Nas reuniões de vizinhos Emilie pergunta a Arminda, "a minhota risonha que enfrentava os momentos mais difíceis da vida com um sorriso eterno que dividia seu rosto” (Hatoum 2008: 35),

se tinha notícias dos parentes portugueses, e a dona Sara Benemou quando a sinagoga seria inaugurada e se em Rabat conheciam o tabule e a esfiha com picadinho de carneiro, e a todos os convivas, com um olhar aceso e abrangente, se já sabiam que Dorner estava de volta à cidade (idem, p. 36).

Ainda que frequente, esse convívio nem sempre é pacífico, havendo episódios de incompreensão, intolerância e até de confronto, que revelam uma rivalidade ancestral no terreno das crenças religiosas. Assim, por exemplo, o comerciante muçulmano de Relato de um certo Oriente vai reprovar a crueldade de Hindié Conceição na matança dos perus para a ceia do Natal, argumentando que "esse martírio só pode ser obra de cristão" (Hatoum 2008: 32). A oposição entre as diferentes comunidades tinge-se de intolerância religiosa quando se trata de casamentos cruzados, como no episódio em que as maronitas de Manaus protestam animosamente contra a união de Zana e do muçulmano Halim:

Logo todos na cidade souberam. Halim se embeiçara por Zana. As cristianas maronitas de Manaus, velhas e moças, não acertavam a ideia de ver Zana casar-se com um muçulmano. Ficavam de vigília na calçada do Biblos, encomendavam novenas para que ela não se casasse com Halim. Diziam a Deus e ao mundo fuxicos assim: que ele era um mascate, um teque-teque qualquer, um rude, um maometano das montanhas do sul do Líbano, que se vestia como um pé rapado e matraqueava nas ruas e praças de Manaus (idem, 40).

No entanto, a religião, com significativas exceções nalguns episódios, como o acima citado, parece não causar desavenças entre os casais árabes dos dois romances, em que a mulher é cristã e o marido muçulmano. $\mathrm{O}$ fervor religioso de cada um é encarado com naturalidade pelo 
outro, as suas celebrações rituais são toleradas, às vezes com desdém e ironia, é certo, mas na maioria dos casos com a consciência de que sob o sol de Manaus há e haverá sempre lugar para todos os homens e todos os Deuses.

O convívio entre culturas nutre, assim, o quotidiano de uma população urbana multicultural que, ainda que conserve os traços mais entranhados da sua identidade étnica originária, se vai modificando na coexistência com o Outro. A força revitalizadora da seiva amazónica transmuta infalivelmente o destino das árvores arrancadas do solo natal para serem transplantadas numa terra alheia. Com a morte das matriarcas nos dois romances, Emilie e Zana, extingue-se tudo aquilo que restara da identidade pura das origens e essa extinção é cifrada na perda e ruína das casas familiares. A consciência das origens árabes ainda permanece viva nos filhos e netos dos imigrantes - em Yaqub, Hakim, Omar e Nael - mas eles abandonam o lar, para construir uma vida independente que lhes confirmará a identidade híbrida de descendentes de árabes, crescidos em solo brasileiro e alimentados por uma nova realidade em que se misturam as variadas culturas das etnias locais e dos imigrantes vindos de diversos cantos do mundo. Na época de culturas globalizadas e de identidades ameaçadas que transitam pelos não-lugares de uma história em crescente aceleração, a ficção pode, e Relato de um certo Oriente e Dois irmãos, de Milton Hatoum, são um claro exemplo disso, representar um projeto sólido e sistemático de recentrar o interesse da literatura no problema da fixação da identidade, através da preservação de uma memória textual dos antepassados e de maneira a poder enfrentar a inconsistência das existências individuais, quando privadas da memória das origens que constrói toda e qualquer identidade.

\section{Referências bibliográficas}

Hatoum, M. (2006). Dois irmãos. São Paulo: Companhia das Letras.

(2008). Relato de um certo Oriente. São Paulo: Companhia das Letras.

Mott, M. L. (2007). Imigração árabe: um certo oriente no Brasil. - In Instituto Brasileiro de Geografia e Estatística, Brasil: 500 anos de povoamento (pp. 179-196). Rio de Janeiro: IBGE. http://biblioteca.ibge. gov.br/visualizacao/livros/liv6687.pdf, 19.09.2014. 
